\title{
Perioperative management and monitoring of antiplatelet agents: a focused review on aspirin and P2Y $_{12}$ inhibitors
}

\author{
Michael A. Mazzeffi ${ }^{1}$, Khang Lee ${ }^{1}$, Bradley Taylor ${ }^{2}$, and Kenichi A. Tanaka ${ }^{1}$ \\ ${ }^{1}$ Department of Anesthesiology, University of Maryland School of Medicine, ${ }^{2}$ Department of Surgery, Division of \\ Cardiac Surgery, University of Maryland School of Medicine, Baltimore, MD, USA
}

Platelets play pivotal roles in hemostasis as well as pathological arterial thrombosis. The combination of aspirin and a $\mathrm{P}_{2} \mathrm{Y}_{12}$ inhibitor has become the mainstay therapy in the ageing population with cardiovascular conditions, particularly during and after percutaneous coronary intervention. A number of novel P2 $\mathrm{Y}_{12}$ inhibitors has become available in the recent years, and they markedly vary in pharmacokinetic and pharmacodynamic properties. Perioperative physicians today face a challenge of preventing hemorrhage due to platelet inhibitors, while minimizing thrombotic risks. There are several point-of-care platelet function tests available in the peri-procedural assessment of residual platelet aggregation. However, these platelet function tests are not standardized in terms of sample processing, agonist type and potency as well as methods of detecting platelet activity. Understanding the differences in pharmacological properties of antiplatelet agents, principles of platelet function tests, and pertinent hemostatic strategies may be useful to anesthesiologists and intensivists who manage perioperative issues associated with antiplatelet agents. The objectives of this review are: 1) to discuss clinical data on aspirin and $\mathrm{P} 2 \mathrm{Y}_{12}$ inhibitors relating to perioperative bleeding, 2) to outline different features of point-of-care platelet function tests, and 3) to discuss therapeutic options for the prevention and treatment of bleeding associated with antiplatelet agents.

Key Words: Antiplatelet therapy, Aspirin, Bleeding, Platelet, $\mathrm{P}_{2} \mathrm{Y}_{12}$ inhibitor, Transfusion.

Corresponding author: Kenichi A. Tanaka, M.D.

Department of Anesthesiology, University of Maryland School of Medicine, 22 South Greene Street, Suite S8D12, Baltimore, MD 21201, USA

Tel: 1-410-328-9813

Email: ktanaka@som.umaryland.edu

ORCID: https://orcid.org/0000-0002-5051-1365

Received: June 20, 2017.

Accepted: June 26, 2017.

Korean J Anesthesiol 2017 August 70(4): 379-389

https://doi.org/10.4097/kjae.2017.70.4.379

\section{Introduction}

Antiplatelet therapy has become the cornerstone of clinical management of acute coronary syndrome (ACS). There has been extensive research into both physiological and pathological roles that platelets play in hemostasis and thrombosis for more than half a century. Antithrombotic properties of aspirin were recognized as early as in the 1950's [1], but aspirin's cardioprotective effects were confirmed merely two decades ago [2]. The development of percutaneous coronary intervention (PCI) was the driving force behind the evolution of antiplatelet regimen as a prevention for early stent thrombosis. Different classes of antiplatelet agents have been introduced since late 1990's, which include the glycoprotein IIb/IIIa (GPIIb/IIIa) receptor antagonists, and thienopyridine derivatives $[3,4]$. A method to evaluate

(c) This is an open-access article distributed under the terms of the Creative Commons Attribution Non-Commercial License (http://creativecommons.org/ licenses/by-nc/4.0/), which permits unrestricted non-commercial use, distribution, and reproduction in any medium, provided the original work is properly cited. 
platelet function was originally described by Professor Born [5] in the form of a light transmission platelet aggregometry in the 1960 's. However, platelet function testing was not widely adopted in monitoring antiplatelet therapies until a simple whole blood test format became available [6]. The importance of platelet function testing has drawn more attention after high ontreatment platelet reactivity (HPR) was reported to increase major adverse cardiac events (MACE) after PCI [7,8]. Conversely, extremely decreased (low on-treatment) platelet activity upon testing may be regarded as an increased risk for bleeding complications $[9,10]$, therefore dosing of the respective agents needs to be carefully adjusted in patients at high risk for bleeding.

Today, physicians are required to manage complex coagulation problems of critically ill patients, and therefore understanding of current antiplatelet agents, hemostasis monitoring and therapeutic strategies is quite important. The aims of this article are to review the role of dual antiplatelet therapy, and to discuss clinical implications of platelet function testing in preventing thrombosis and hemorrhage in the perioperative setting.

\section{Platelet Inhibitors and Cardiac Surgery}

\section{Aspirin}

The majority of patients with coronary artery disease (CAD) or peripheral vascular disease take aspirin for primary or secondary prevention of thrombotic events. Aspirin (acetylsalicylic acid) exerts its antiplatelet activity via rapid-irreversible inhibition of the cyclooxygenase-1 enzyme [11], inhibiting the conversion of arachidonic acid to thromboxane $\mathrm{A}_{2}\left(\mathrm{TXA}_{2}\right)$. Platelet aggregation via the thromboxane-prostanoid (TP) receptor is thus inhibited after aspirin ingestion. Because thromboxane expression is increased during inflammatory states (e.g., surgery), aspirin has the potential to decrease platelet aggregation during the perioperative period. Aspirin may be beneficial as an antiinflammatory and antithrombotic agent, but it may also increase the risk of bleeding.

There is mixed evidence about whether to withhold aspirin during the perioperative period in patients with cardiovascular disease. Potential reasons to continue aspirin are prevention of perioperative myocardial ischemia, stent thrombosis, and stroke. However, in the POISE-2 trial (Perioperative Ischemic Evaluation-2; NCT01082874) continuation of aspirin during the perioperative period did not decrease the risk of stroke or myocardial infarction (MI) in "non-cardiac" surgical patients. The main argument for withholding aspirin is to decrease major bleeding, which appeared to increase in the aspirin versus the placebo cohort (hazard ratio 1.23; 95\% CI 1.01-1.49) according to the POISE-2. However, aspirin was not reported to increase perioperative bleeding in several large observational studies in- volving cardiac surgical patients receiving aspirin before or early after surgery $[12,13]$. In a recent prospective randomized controlled trial of coronary artery bypass surgery (CABG) patients, aspirin was not associated with increased bleeding [14]. Further, perioperative aspirin use may be beneficial in cardiac surgery, decreasing complications such as MI and renal failure after surgery $[12,13,15]$. Aspirin may even confer a lung protective effect after massive transfusion after cardiac surgery as reported in one observational study [16].

Lack of aspirin-associated bleeding in contemporary cardiac surgical patients may be due to the ubiquitous use of antifibrinolytics. In a large randomized controlled trial of tranexamic acid (TA) in CABG patients, the risk for major bleeding was decreased by approximately 50\% with TA [17]. Taken together, patients are likely to be continued on aspirin through most of the perioperative period due to lack of higher level evidence to withhold it before cardiovascular surgery.

\section{$\mathrm{P} 2 \mathrm{Y}_{12}$ inhibitors}

In the early 1990s, aspirin was used in conjunction with heparin or warfarin after bare-metal coronary stent placement, but the stent thrombosis rate was still 3.5\%, and bleeding complications were not uncommon [18]. Dual antiplatelet therapy (DAPT) using aspirin and ticlopidine, a thienopyridine $\mathrm{P}_{2} \mathrm{Y}_{12}$ inhibitor, was introduced, decreasing the rate of stent thrombosis to about $1 \%$ [4]. The 2nd generation thienopyridine, clopidogrel is now widely used in the setting of ACS and PCI [19]. Activation of $\mathrm{P} 2 \mathrm{Y}_{12}$ receptor is crucial in sustained platelet aggregation induced by adenosine diphosphate (ADP) at the vascular injury site [20].

The introduction of drug-eluting stents (DES) reduced instent restenosis by inhibiting neointimal hyperplasia, but the risk of stent thrombosis remained high due to delayed re-endothelialization. Minimum duration of DAPT is an evolving concept, but at least 6 and 12 months of DAPT are recommended after DES placement for stable CAD and ACS, respectively according to the 2016 update of the ACC/AHA guideline [21]. In the case of high-risk bleeders, durations may be shortened to 3 and 6 months in stable CAD and ACS, respectively [21,22]. Aspirin monotherapy is generally sufficient for elective CABG patients with stable CAD, but 6-12 months of DAPT are recommended for CABG patients with recent ACS and/or PCI [21].

Currently available $\mathrm{P} 2 \mathrm{Y}_{12}$ platelet inhibitors are shown (Fig. 1). Clopidogrel is a widedly used thienopyridine prodrug, which undergoes 2-step hepatic metabolism involving cytochrome P450 (CYP). Its antiplatelet activity may be influenced by polymorphisms of CYP2C19. A higher incidence of poor metabolizers in Korean and Japanese populations has been reported than elsewhere [23]. The genotypes CYP2C19*2 and CYP2C19*3 
Clopidogrel active metabolite Mol. wt 355.84<smiles>COC(=O)[C@@H](c1ccccc1Cl)N1CC[C@H](S)/C(=C\C(=O)O)C1</smiles>

Prasugrel active metabolite Mol. wt 373.44<smiles>O=C(O)/C=C1/CN(C(C(=O)C2CC2)c2ccccc2F)CCC1S</smiles>

Adenosine diphosphate Mol. wt 427.20<smiles>Nc1ncnc2c1ncn2[C@@H]1O[C@H](COP(=O)(O)OP(=O)(O)O)[C@@H](O)[C@H]1O</smiles>

Ticagrelor

Mol. wt 522.57

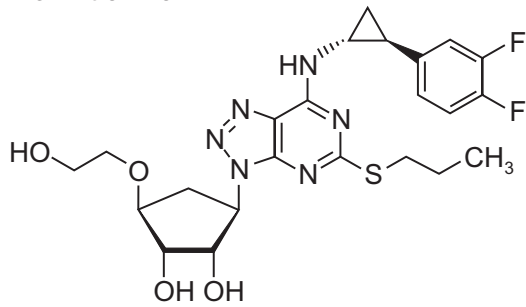

Cangrelor

Mol. wt 864.30

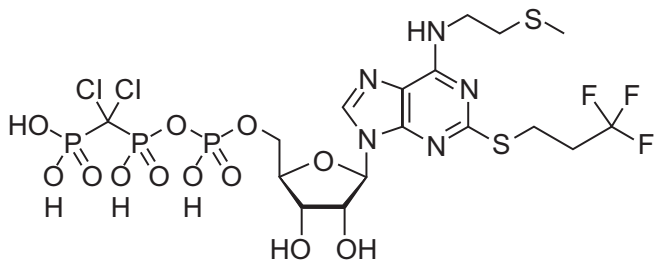

Fig. 1. Chemical structures of $\mathrm{P} 2 \mathrm{Y}_{12}$ inhibitors. Chemical structures of $\mathrm{P}_{2} \mathrm{Y}_{12}$ inhibitors are shown with their molecular weights (Mol. wt) along with a $\mathrm{P}_{2} \mathrm{Y}_{12}$ agonist, adenosine diphosphate. represent a "slow metabolizer" of clopidogrel or "non-responder." HPR is in part attributed to gene polymorphisms, which appear to increase the rate of MACE while on aspirin and clopidogrel after DES implantation [24].

The 3rd generaiton thienopyridine, prasugrel is also a prodrug, but is rapidly activated via single CYP450-mediated oxidation [25]. Prasugrel is thus presumed to be less prone to CYP polymorphisms, and have more predictablle pharmacokinetics. Efficacy and safety of prasugrel were compared with clopidogrel in moderate-high risk ACS patients undergoing PCI $(\mathrm{n}=3,534)$ in TRITON-TIMI 38 (Trial to Assess Improvement in Therapeutic Outcomes by Optimizing Platelet Inhibition With Prasugrel-Thrombolysis In Myocardial Infarction 38; NCT00097591) [26]. Prasugrel was associated with decreased risk of 30-day MACE compared to clopidogrel (6.5\% vs. 9.5\%) (hazard ratio $0.69 ; 95 \%$ CI $0.54-0.87 ; \mathrm{P}=0.0017)$. Less than $4 \%$ of studied patients underwent CABG, but TIMI major bleeding ${ }^{1)}$ after CABG was reported more frequently in the prasugrel group (12 of 64; $18.8 \%$ ) than in the clopidogrel group (2 of $73 ; 2.7 \%$ ) (odds ratio 8.19; 95\% CI 1.76-38.18; $\mathrm{P}=0.0033$ ) [26].

Platelet transfusion was more frequent in the prasugrel group,

\footnotetext{
${ }^{1)}$ Thrombolysis in Myocardial Infarction (TIMI) non-CABG-related major bleeding is defined as intracranial or clinically significant bleeding with a decrease in hemoglobin $\geq 5 \mathrm{~g} / \mathrm{dl}$.
}

but only trends for increased transfusion of packed red blood cells (PRBC) and plasma were observed. The timing of stopping thienopyridines was shown to be important in this study. When prasugrel was stopped more than 7 days before CABG, postoperative blood loss and transfusion requirements were similar to the clopidogrel group [27]. It is possible that hemorrhagic side effect of prasugrel may be modulated by dose adjustment in patients at high risk for bleeding. In PRASFIT-ACS (Prasugrel compared with clopidogrel for Japanese patients with ACS undergoing PCI), one-third dose of prasugrel that is used in United States/Europe was evaluated against the standard dose of clopidogrel (Table 1) [28]. The incidence of MACE was numerically lower with prasugrel compared to clopidogrel, although the difference was not statistically significant ( $9.4 \%$ vs. $11.8 \%$; hazard ratio $0.77 ; 95 \%$ CI $0.56-1.07)$. The incidence of the composite of major, minor, and clinically-relevant bleeding was $9.6 \%$ in both prasugrel and clopidogrel groups [29]. In the whole cohort $(\mathrm{n}=$ 1,363), pharmacodynamics of prasugrel (i.e., extent of platelet inhibition) was not found to be a bleeding risk factor. The key bleeding risk factors were female gender, low body weight $(\leq 50$ $\mathrm{kg}$ ), advanced age ( $\geq 75$-year-old), and diabetes mellitus in this Japanese cohort [29].

Ticagrelor is a cyclopentyl-triazolo-pyrimidine, which reversibly inhibits $\mathrm{P} 2 \mathrm{Y}_{12}$ receptors in contrast to the covalent bond formation between thienopyridines and ADP binding sites [30]. 
Table 1. $\mathrm{P} 2 \mathrm{Y}_{12}$ Inhibitors and Bleeding Complications (Clopidogrel as a Comparator)

\begin{tabular}{lcccc}
\hline & \multicolumn{2}{c}{ Prasugrel } & Ticagrelor & Cangrelor \\
\hline Study name & TRITON-TIMI 38 & PRASFIT-ACS & PLATO & CHAMPION-PHOENIX \\
Total cohort size & 6,741 & 1,363 & 18,624 & 11,145 \\
Study duration & $15 \mathrm{months}$ & $24 \mathrm{weeks}$ & $12 \mathrm{months}$ & $48 \mathrm{~h}$ \\
Loading/maintenance dose & $60 \mathrm{mg} / 10 \mathrm{mg}$ & $20 \mathrm{mg} / 3.75 \mathrm{mg}$ & $180 \mathrm{mg} / 90 \mathrm{mg}$ & $30 \mu \mathrm{gg} / \mathrm{kg} \mathrm{iv} / \mathrm{infusion} 4 \mu \mathrm{g} / \mathrm{kg} / \mathrm{min}$ \\
Primary outcome* & $0.82(0.39-1.73)$ & $0.77(0.56-1.07)$ & $0.84(0.77-0.92)$ & $0.78(0.66-0.93)$ \\
Non-CABG major bleed & $1.32(1.03-1.68)$ & $0.82(0.39-1.73)$ & $1.25(1.03-1.53)$ & $1.0(0.29-3.45)$ \\
CABG-related major bleed & $4.73(1.90-11.8)$ & $1.76(0.51-6.00)$ & $0.94(0.82-1.07)$ & $0.9(0.4-2.2)$ \\
\hline
\end{tabular}

Values are in odds ratio (95\% CI) compared to the cohort receiving the standard dose of clopidogrel (300 mg loading, $75 \mathrm{mg}$ maintenace) except for cangrelor (compared to clopidogrel $300 \mathrm{mg}$ loading). *MACE: a composite event rate of cardiovascular death, nonfatal myocardial infarction, and nonfatal ischemic stroke, CABG: coronary artery bypass graft surgery, TRITON-TIMI 38 [26]: Trial to Assess Improvement in Therapeutic Outcomes by Optimizing Platelet Inhibition With Prasugrel-Thrombolysis In Myocardial Infarction 38, PRASFIT-ACS [28]; Prasugrel compared with clopidogrel for Japanese patients with ACS undergoing PCI, PLATO trial [31]: Platelet Inhibition and Patient Outcomes, CHAMPION-PHOENIX [37]: Cangrelor versus Standard Therapy to Achieve Optimal Management of Platelet Inhibition.

A lower risk of bleeding was initially anticipated for ticagrelor, but no difference in the risk of CABG-related bleeding was demonstrated between ticagrelor and clopidogrel groups in the prospective randomized PLATO trial (Platelet Inhibition and Patient Outcomes; NCT00391872) involving 18,624 patients [31]. Within the ticagrelor group, a significantly higher risk of CABG-related bleeding was recognized when the time of surgery was less than $72 \mathrm{~h}$ from drug discontinuation [32]. The odds ratio of bleeding was 5 -fold increased in this cohort when compared to 2 cohorts with $72-120 \mathrm{~h}$ and $>120 \mathrm{~h}$ of discontinuation. Major bleeding was more common with both ticagrelor and clopidogrel when drug discontinuation was within $24 \mathrm{~h}$ of CABG; the incidences of bleeding were $38 \%$ and $31 \%$, respectively according to the BARC-CABG definition [33]. ${ }^{2)}$

Cangrelor is a non-thienopyridine and modified ADP derivative with an extremely short half-life (3-6 $\mathrm{min}$ ) [34,35]. Platelet inhibition (> 80\%) is rapidly achieved after a loading dose of 30 $\mu \mathrm{g} / \mathrm{kg}$ followed by $4 \mu \mathrm{g} / \mathrm{kg} / \mathrm{min}$ infusion, while a full recovery of platelet function is observed in $\sim 60 \mathrm{~min}$ of drug discontinuation (Fig. 2) [36]. The CHAMPION-PHOENIX trial (Cangrelor versus Standard Therapy to Achieve Optimal Management of Platelet Inhibition; NCT01156571) is a comparison of cangrelor and clopidogrel $(n=11,145)$ in the ACS setting, which reported that stent thrombosis was developed in $0.8 \%$ and $1.4 \%$, respectively (odds ratio 0.62; 95\% CI 0.43-0.90; $\mathrm{P}=0.005$ ) [37]. The major side effect of cangrelor is a transient dyspnea, which occurred in $1.2 \%$ of cangrelor-treated subjects. Utility of cangrelor in a transition from thienopyridines to major cardiac surgery was tested in the BRIDGE trial in which cangrelor or placebo was infused up to 7 days before CABG [38]. Cangrelor was stopped

\footnotetext{
${ }^{2)}$ BARC type 4 CABG-related bleeding is defined as bleeding resulting in death, or reoperation due to bleeding, or intracranial haemorrhage, or transfusion of 5 or more units of PRBC over $48 \mathrm{~h}$, or chest tube drainage in excess of $2 \mathrm{~L}$ over $24 \mathrm{~h}$.
}

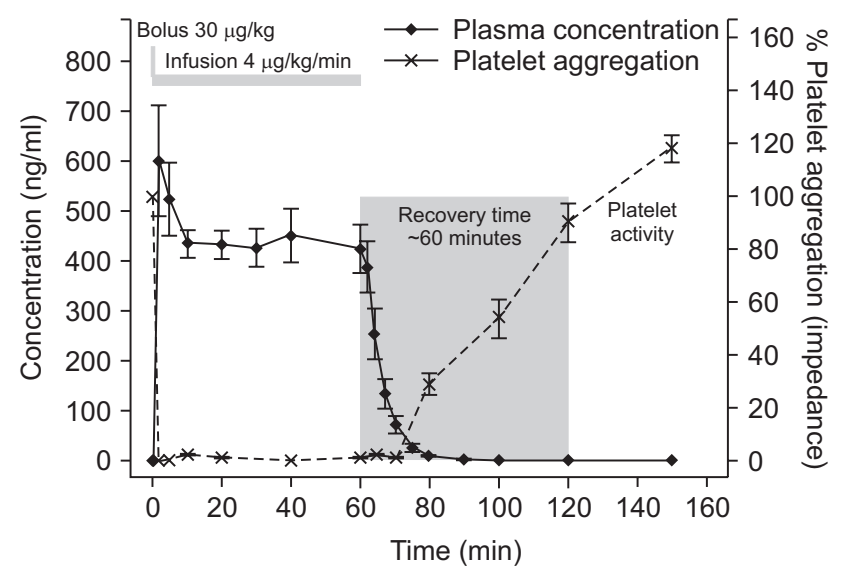

Fig. 2. Pharmakokinetics and Pharmakodynamics of cangrelor. Platelet aggregation in response to $20 \mu \mathrm{M}$ adenosine diphosphate is minimal after a bolus dose $(30 \mu \mathrm{g} / \mathrm{kg})$, and suppressed for the duration of cangrelor infusion (4 $\mu \mathrm{g} / \mathrm{kg} / \mathrm{min}$ for $60 \mathrm{~min}$ ) [36]. After stopping infusion, platelet aggregation is restored to the baseline in $60 \mathrm{~min}$.

1-6 $\mathrm{h}$ before surgery, and there was no significant difference in CABG-related major bleeding between placebo and cangrelor $(10.4 \%$ vs. $11.8 \%)$. Preoperative platelet inhibition $(>60 \%)$ in the cangrelor group did not lead to a statistically significant reduction in ischemic events ( $2.8 \%$ vs. placebo $4.0 \%$ ). Minor bleeding incidences were more frequent in the cangrelor group before surgery, but there was no significant difference from the placebo in terms of major bleeding events.

Taken together, various $\mathrm{P}_{2} \mathrm{Y}_{12}$ inhibitor agents are being utilized extensively in high-risk CAD patients who might present to elective and urgent cardiovascular surgery. It is crucial to understand differences in pharmakinetics and pharmacodynamics among different $\mathrm{P} 2 \mathrm{Y}_{12}$ inhibitors, so that perioperative risks of ischemia, stent thrombosis, and bleeding can be minimized. 


\section{Platelet Function Tests}

Variability in response to antiplatelet agents, and noncompliance raise the importance of testing platelet function in patients on DAPT. Light transmission aggregometry (LTA) in platelet-rich plasma has been the gold standard in platelet function testing. However, LTA is technically cumbersome, and time-consuming, and therefore it was not widely utilized in the perioperative setting beyond the assessment of congenital platelet disorders [39]. In the recent years, several whole blood platelet function tests have become commercially available, and some are used as a point-of-care (POC) test. However, each device has different features including sample processing, type and potency of platelet agonists, and method of detecting platelet activity [40]. In the following section, key features and clinical utilities of several POC devices will be discussed.

The VerifyNow ${ }^{\circledR}$ system (Accriva Diagnostics, San Diego, CA, USA) has been extensively studied in clinical trials involving $\mathrm{P}_{2} \mathrm{Y}_{12}$ inhibitors in the North America [41]. $\mathrm{P} 2 \mathrm{Y}_{12}$ reaction unit (PRU) is automatically measured in citrated whole blood mixed with a lyophilized ADP $(20 \mu \mathrm{M})$, prostaglandin $\mathrm{E}_{1}\left(\mathrm{PGE}_{1}\right.$; $22 \mathrm{nM}$ ) and fibrinogen-coated polystyrene beads. Agglutination between activated platelets and fibrinogen-coated beads causes an increase in light transmission, which is used to calculate "PRU." The presence of $\mathrm{PGE}_{1}$ elevates intra-platelet cyclic adenosine monophosphate, making platelet activation more dependent on $\mathrm{P} 2 \mathrm{Y}_{12}$ activation. Normal PRU is reported in the range of $180-376$, and $\mathrm{P} 2 \mathrm{Y}_{12}$ inhibition is assumed for PRU below 180. HPR was defined as PRU above 208 on clopidogrel in a prospective randomized study involving stable CAD with at least 1 coronary stent $(\mathrm{n}=423)$, comparing prasugrel $10 \mathrm{mg}$ versus clopidogrel $75 \mathrm{mg}$ daily. After 3 months of intervention, PRU (median, interquartile range) decreased from 245 (225-273) to $80(42-124)$ in 212 patients who were switched to prasugrel, while PRU values were 241 (194-275) in 211 patients who remained on clopidogrel. The primary endpoint of cardiac death or myocardial infarction at 6 months occurred in very few patients, and thus clinical implication of HPR was not demonstrated. During 6 months period, major bleeding occurred in 3 patients $(1.4 \%)$ on prasugrel, and 1 patient $(0.5 \%)$ on clopidogrel. As mentioned, low-dose regimen of prasugrel was tested in Japan in ACS patients undergoing PCI, and it was non-inferior to the standard dose of clopidogrel (Table 1). The prevalence of HPR (PRU > 208) was reduced after switching to prasugrel from clopidogrel in a subset $(n=53)$ of slow metabolizers (CYP2C19*2/CYP2C19*3) [42]. Baseline PRU values (mean \pm SD) were similar in the prasugrel and clopidogrel groups (231 \pm 57 vs. $237 \pm 58, \mathrm{P}=0.65)$. PRU values were lower with prasugrel than clopidogrel at $24 \mathrm{~h}(147 \pm 80$ vs. $261 \pm 57, \mathrm{P}<0.001)$, and in 2 weeks ( $171 \pm 67$ vs. $221 \pm 70, \mathrm{P}=0.005)$. No specific thresh- old PRU values predictive of non-CABG major bleeding events were found, but bleeding risks were associated with females, low body weight ( $\leq 50 \mathrm{~kg}$ ), advanced age ( $\geq 75$-year-old), and diabetes mellitus [29].

VerifyNow $^{\circledR}$ system can be thus used to assess pre-procedural P2 $\mathrm{Y}_{12}$ blockade [43]. However, its intra- and post-operative uses can be hindered by low hematocrit, which spuriously increase PRU values [44].

The Multiplate ${ }^{\circledR}$ system (Roche Diagnostics, Rotkreuz, Switzeland) is a whole blood impedance aggregometry commonly used in cardiology and perioperative settings in Europe. Whole blood is collected in a hirudin tube, and each sample (300 $\mu \mathrm{l})$ is mixed with normal saline $(300 \mu \mathrm{l})$ in a test well containing 2 independent sensor units (electrode wires). For $\mathrm{P}_{2} \mathrm{Y}_{12}$ testing, $\operatorname{ADP}(6.4 \mu \mathrm{M})$ is added as an agonist, and electrical impedance changes are monitored while activated platelets adhere to the electrodes. Impedance changes in 2 sensor units are traced for 6 min, which are averaged to calculate area under the curve (AU $\mathrm{x}$ min). One Multiplate ${ }^{\circledR}$ unit (U) is defined as $10 \mathrm{AU} x \mathrm{~min}$, and normal ADP response is 57-113 U. In a PCI study involving 2,533 patients receiving a loading dose of clopidogrel (600 mg), Multiplate ${ }^{\circledR}$ ADP test value below $19 \mathrm{U}(\mathrm{n}=975)$ was associated with a 2.6-fold higher major bleeding risk after PCI [45]. In the surgical setting, there is a paucity of data on the optimal threshold on Multiplate ${ }^{\circledR}$ ADP test that might predict increased bleeding and platelet transfusion. In a single-center study involving 87 patients on ticlopidine or clopidogrel, ADP test below $31 \mathrm{U}$ before surgery was reported as an optimal cut-off (sensitivity $72 \%$, specificity $66 \%$ ) for increased bleeding (> $800 \mathrm{ml}$ in $12 \mathrm{~h}$ ). However, the size of bleeding cohort was small $(n=14)$, and intra/post-operative ADP results were not included. A larger clinical study is warranted to validate the role of intra/post-operative monitoring of ADP response [46,47].

TEG $^{\circledR}$ Platelet Mapping ${ }^{\text {TM }}$ (Haemonetics, Braintree, MA, USA) is the thrombelastography-based platelet function test for monitoring aspirin or $\mathrm{P}_{2} \mathrm{Y}_{12}$ inhibitors. For $\mathrm{P}_{2} \mathrm{Y}_{12}$ inhibitior assay, heparinized whole blood is mixed with $\operatorname{ADP}(2 \mu \mathrm{M})$ and Activator $\mathrm{F}^{\mathrm{TM}}$ (reptilase and activated FXIII), which separately trigger platelet activation and fibrin polymerization, respectively. ADP-stimulated maximum amplitude $\left(\mathrm{MA}_{\mathrm{ADP}}\right)$ and fibrinspecific MA $\left(\mathrm{MA}_{\mathrm{Fib}}\right)$ are used to calculate platelet inhibition in reference to thrombin-mediated $\mathrm{MA}\left(\mathrm{MA}_{\text {Thrombin }}\right)$ using the standard kaolin TEG $^{\circledR}$ (Fig. 3A) as follows;

$$
\begin{gathered}
\% \text { Platelet inhibition = } 100-\left[\left(\mathrm{MA}_{\mathrm{ADP}}-\mathrm{MA}_{\mathrm{Fib}}\right) \div\right. \\
\left.\left(\mathrm{MA}_{\text {Thrombin }}-\mathrm{MA}_{\mathrm{Fib}}\right) \times 100\right]
\end{gathered}
$$

Alternatively, area under the curve of ADP-stimulated TEG ${ }^{\circledR}$ waveform at $15 \mathrm{~min}\left(\mathrm{AUC}_{15}\right)$ is used for a faster result (short TEG $^{\circledR}$ ) (Fig. 3B) [48,49]. HPR during clopidogrel therapy is de- 
A

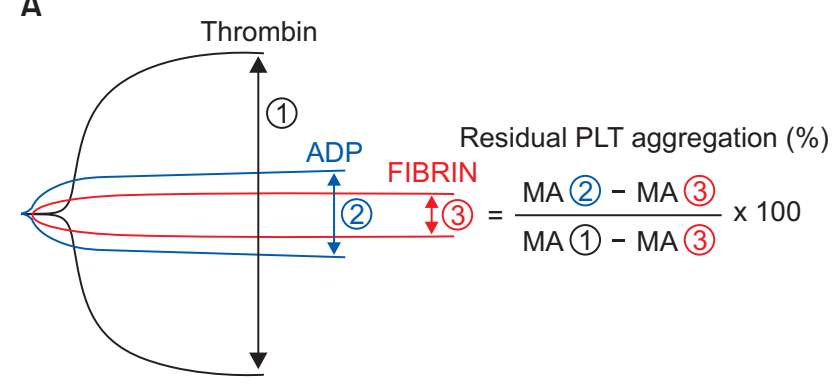

B

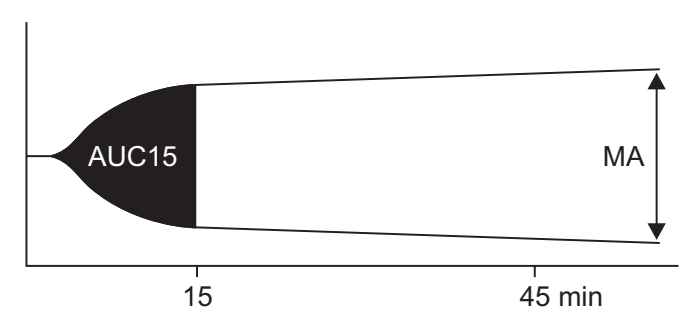

Fig. 3. Principles of Platelet Mapping ${ }^{\mathrm{TM}}$. (A) Platelet (PLT) aggregation is calculated from 3 separate tests on thrombelastography $\left(\right.$ TEG $\left.^{\circledR}\right)$. Thrombin-activated (1) and adenosine diphosphate-activated (2)) maximum amplitude (MA) values are compared relative to fibrinspecific channel (3)). (B) Short $\mathrm{TEG}^{\circledR}$ utilizes the area under the curve of TEG ${ }^{\circledR}$ signals from the first $15 \mathrm{~min}$ (area under the curve [AUC] 15). This allows a faster assessment on platelet inhibition because time to MA may be prolonged (> $60 \mathrm{~min}$ ) in some cases $[48,49]$.

fined as $<30 \%$ decrease in $\mathrm{AUC}_{15}$ in the $\mathrm{ADP}$ channel relative to the kaolin channel [48].

In one preoperative platelet assessment study involving clopidogrel-treated and untreated patients, the mean $\mathrm{MA}_{\mathrm{ADP}}$ in the clopidogrel group was lower, but there was a significant overlap in the calculated \% platelet inhibition between the control (47.8 $\pm 18.9 \%)$ and clopidogrel treatment $(71.5 \pm 18.4 \%)$ [50]. This non-specificity may be attributed to a lower ADP concentration used in the Platelet Mapping ${ }^{\mathrm{TM}}$ assay, and its \% inhibiton cannot be generalized to other platelet function tests.

Stratifying CABG patients to a specific waiting period based on the $\mathrm{MA}_{\mathrm{ADP}}$ (3-5 days for $35-50 \mathrm{~mm}$, and $>5$ days for $<35$ $\mathrm{mm}$ ) was previously evaluated in the clopidogrel-treated $(\mathrm{n}=$ $86)$ and untreated control patients $(n=94)$ [51]. The average waiting was reduced by $46 \%$ to 2.7 days versus the standard 5 days in the clopidogrel group, and similar PRBC transfusion rate and postoperative bleeding were reported between 2 groups [51]. Intra/post-operative uses of Platelet Mapping ${ }^{\mathrm{TM}}$ may be hindered by fluctuating fibrinogen and hematocrit levels.

In summary, POC assessment of platelet $\mathrm{P}_{2} \mathrm{Y}_{12}$ function has become feasible, and useful in optimizing the timing of surgery, but the results from different tests are not interchangeable. Further, evidence that supports intraoperative platelet function testing is rather limited for the predictions of bleeding, and need for platelet transfusion.

\section{Effects of Cardiopulmonary Bypass on Platelet Function Tests}

Use of cardiopulmonary bypass (CPB) affects platelet count and function in multiple ways. To name a few, heparin, protamine, and hypothermia modulate platelet activity [52-54]. Sequestration of platelets in the spleen and liver occurs under hypothermia [55], and thrombocytopenia resulting from hemodilution (crystalloid or colloid solution) is not uncommon [56].

Assessment of platelet function before and after CPB using LTA and multiple electrode aggregometry has demonstrated that the platelet responses to $\mathrm{TXA}_{2}$ and ADP are decreased immediately after $\mathrm{CPB}$ regardless of the status of preoperative platelet inhibition, or adjustments of platelet counts in test samples (as performed in LTA) $[47,57,58]$. These data indicate that platelet surface $\mathrm{TP}$ and/or ADP receptors are temporarily less responsive to agonist stimulation when hemostasis needs to be established after CPB. Postoperatively platelet function appears to recover gradually after $3 \mathrm{~h}$, and returns to normal in $24 \mathrm{~h}[57,58]$.

Whole blood platelet function tests obtained after CPB often demonstrate abnormal aggregation patterns using various agonists on Multiplate $^{\circledR}$, TEG $^{\circledR}$ Platelet Mapping ${ }^{\mathrm{TM}}$ or Plateletworks $^{\circledR}$ (Helena, Beaumont, TX, USA) [46,47,59-61]. Only a portion of those who demonstrate a below-normal platelet function require actual platelet transfusion $[46,59]$.

Testing platelet function as routine part of transfusion algorithm remains controversial. Intraoperative POC use of Multiplate ${ }^{\circledR}$ did not result in statistically significant reduction in platelet transfusion, but ROTEM $^{\circledR}$ use effectively reduced plasma transfusion in 100 cardiac surgical patients randomized to conventional care or POC-based management [46].

Conversely, in a large scale prospective before-and-after trial (stepped-wedge clustered randomized study) involving 7,402 patients, relative risks of PRBC transfusion, and platelet transfusion were reduced after the POC implementation $\left(\right.$ ROTEM $^{\circledR}$ and Plateletworks $\left.{ }^{\circledR} ; \mathrm{n}=3,847\right)$; adjusted relative risk $0.91(95 \%$ CI 0.85-0.98; $\mathrm{P}=0.02)$ for $\mathrm{PRBC}$, and relative risk $0.77(95 \%$ CI, 0.68-0.87; $\mathrm{P}<0.001$ ) for platelets [62]. There was noticeable variability in blood product usage among 12 study sites, and POC testing did not reduce plasma usage. Indeed, transfusions of platelets and plasma occurred in up to $40 \%$ of patients at some sites even after POC implementation.

\section{Platelet Transfusion and Adjunct Therapies}

There is a paucity of data on the clinical efficacy of allogeneic platelet transfusion, particularly for the reversal of $\mathrm{P} 2 \mathrm{Y}_{12}$ inhibitors. In vitro platelet supplementation experiments previously demonstrated that the functional platelet recovery was minimal when freshly prepared platelet concentrate (equivalent to 3-4 
Table 2. Pharmacokinetc Parameters of Aspirin and $\mathrm{P} 2 \mathrm{Y}_{12}$ Inhibitors

\begin{tabular}{lccccc}
\hline & Aspirin & Clopidogrel & Prasugrel & Ticagrelor & Cangrelor \\
\hline Loading dose & $600 \mathrm{mg}$ & $300 \mathrm{mg}$ & $60 \mathrm{mg}$ & $200 \mathrm{mg}$ & $30 \mu \mathrm{mg} / \mathrm{kg}$ \\
Maintenance & & $75 \mathrm{mg}$ & $10 \mathrm{mg}$ & $1.5 \mathrm{~h}$ & $4 \mu \mathrm{gg} / \mathrm{kg} / \mathrm{min}$ \\
$\quad \mathrm{t}_{\max }$ & $0.7 \mathrm{~h}$ & $0.5-1.0 \mathrm{~h}$ & $0.5 \mathrm{~h}$ & $2 \mathrm{~min}$ \\
$\mathrm{C}_{\max }(\mathrm{ng} / \mathrm{ml})$ & 30 & $70 / 28$ & $453 / 56$ & 923 & 635 \\
$\mathrm{AUC}_{0-\mathrm{t}}(\mathrm{ng} / \mathrm{h} / \mathrm{ml})$ & 165 & $90 / 29$ & $460 / 54$ & 6591 & 477 \\
$\mathrm{t}_{1 / 2}$ & $\mathrm{NA}^{*}$ & $\mathrm{NA}^{+}$ & $7.4 \mathrm{~h}$ & $8.4 \mathrm{~h}$ & $3.7 \mathrm{~min}$ \\
\hline
\end{tabular}

Data summarized from references $11,25,30$, and 35 . Loading dose/maintenance doses are indicated for clopidogrel and prasugrel. $t_{\max }$ : time to achieve peak plasma concentration, $\mathrm{C}_{\max }$ : peak plasma concentration of active metabolite, AUC: area under the curve of plasma concentration over time, $\mathrm{t}_{1 / 2}$ : half-life of active metabolite, NA: not available. *Salicylic acid disappears from plasma in $0.25-0.3 \mathrm{~h},{ }^{\dagger}$ active metabolite undetectable within $2-4 \mathrm{~h}$.

apheresis units) was added to the sample blood obtained in 2 $\mathrm{h}$ after the dosing of prasugrel [63] or ticagrelor [64] in addition to aspirin. The half-lives of active metabolites of prasugrel and ticagrelor are approximately $8 \mathrm{~h}$ (Table 2) [25,30], and thus transfused platelets are also susceptible to $\mathrm{P}_{2} \mathrm{Y}_{12}$ inhibition during this interval. On the contrary, $>80 \%$ of normal platelet activity was recovered when the fresh platelet concentrate was supplemented in vitro to blood samples from the subjects whose last doses of clopidogrel and aspirin were $24 \mathrm{~h}$ prior [65].

The age of platelet concentrates is an important consideration in the reversal of $\mathrm{P}_{2} \mathrm{Y}_{12}$ inhibitors in clinical practice. During the storage period of 5 days, platelet aggregation to ADP (5 $\mu \mathrm{M})$ was decreased from $60-70 \%$ at baseline to $24-30 \%$ by day 3 , and $13-25 \%$ by day 5 using 3 different commercial platelet storage bags [66]. Indeed, transfusion of 3-day-old autologous apheresis platelets ( 2 units) in the subjects who received 3-day course of aspirin plus clopidogrel did not normalize ADP (20 $\mu \mathrm{M}$ )-induced platelet aggregation on LTA, but only restored it to 31-38\% (normal, 70\%) in $24 \mathrm{~h}$ [67].

Severe bleeding diathesis refractory to multiple platelet transfusions had been reported after urgent/emergent cardiovascular surgery involving patients who were receiving a potent $\mathrm{P} 2 \mathrm{Y}_{12}$ inhibitor [68]. When faced with emergency surgery in patients on $\mathrm{P} 2 \mathrm{Y}_{12}$ inhibitors, adjunct hemostatic therapies may be necessary to mitigate postoperative hemorrhage refractory to platelet transfusion. Recombinant activated factor VII (rFVIIa, NovoSeven ${ }^{\circledR}$, Bagsbaerd, Denmark) was once touted and used as a "universal hemostastic agent" in many bleeding conditions including post-CPB coagulopathy [69]. Although it may be efficacious, this type of off-label use has been associated with serious thrombotic complications, particularly in the elderly [70]. In a small study involving healthy volunteers who had therapeutic effects of clopidogrel (300 mg, followed by $75 \mathrm{mg}$ for 2 days), 10 and $20 \mu \mathrm{g} / \mathrm{kg}$ of rFVIIa ( $\mathrm{n}=6$ and 12) were shown to reduce the bleeding volume from a standardized punch biopsy wound compared to the placebo $(n=13)$ [71]. This finding is a proof of concept, but efficacy and safety of rFVIIa cannot be extended to cardiac surgical patients who develop multi-factorial coagu- lopathy in addition to platelet $\mathrm{P} 2 \mathrm{Y}_{12}$ inhibition. In a prospective placebo-controlled cardiac surgical study of rFVIIa, bleeding post-CPB patients were randomized to the placebo $(n=68), 40$ $\mu \mathrm{g} / \mathrm{kg}(\mathrm{n}=35)$ or $80 \mu \mathrm{g} / \mathrm{kg}$ of rFVIIa $(\mathrm{n}=69)$. The safety end points of this study indicated that death and cerebral infarction were increased in the rFVIIa cohorts relative to the placebo (odds ratio 1.67; 95\% CI 0.50-5.47), although re-exploration and allogeneic transfusion rates were reduced by rFVIIa [72]. Advanced age ( $\geq 75$-year-old) is an important risk factor for both P2Y $\mathrm{Y}_{12}$ inhibitor related bleeding [29], but it is also associated with rFVIIa-related thrombosis [70]. It is thus important to carefully consider the risk/benefit ratio of these interventions in the elderly.

Desmopressin (d-arginine vasopressin; DDAVP) is a therapeutic agent that is indicated for certain types of von Willebrand disease (vWD) (type 1 and type 2a) [73], and mild hemophilia A [74]. Clinical evidence for the efficacy of DDAVP is rather poor [70], particularly for the reversal of $\mathrm{P}_{2} \mathrm{Y}_{12}$ inhibitors. However, the drug is relatively safe with few serious side effects reported [75]. Plasma levels of high-molecular-weight von Willebrand factor (vWF) multimers are increased from $116 \%$ to $160 \%$ (interquartile range $102-154 \%$ ) with $0.3 \mu \mathrm{g} / \mathrm{kg}$ of DDAVP in postCPB patients without vWD [76]. However, increased vWF levels may not translate into stable thrombus formation in patients on P2 $\mathrm{Y}_{12}$ inhibitors [76].

\section{Antifibrinolytic Therapy and $\mathrm{P}_{2} \mathrm{Y}_{12}$ inhibitors}

Antifibrinolytic therapy has become ubiquitous in cardiac surgical patients, and is currently a Class 1a recommendation in the 2012 STS/SCA ${ }^{3)}$ guideline [77]. However, it remains unclear to what degree antifibrinolytics ( $\varepsilon$-aminocaproic acid or TA) can mitigate hemorrhagic side effects of potent ADP inhibitors such as clopidogrel, prasugrel, and ticagrelor. In one randomized controlled trial that included 570 CABG patients, $10 \mathrm{mg} / \mathrm{kg}$ bolus of TA, followed by an infusion of $10 \mathrm{mg} / \mathrm{kg} / \mathrm{h}$ reduced blood loss

\footnotetext{
${ }^{3)}$ Society for Thoracic Surgeons and Society of Cardiovascular Anesthesiologists.
} 
when compared to controls that did not receive TA. This study suggested that TA's beneficial effects were greater in patients who received clopidogrel within 7 days of surgery, meaning there was more reduction in blood loss in this group. These findings associated with TA in clopidogrel-treated patients cannot be simply inferred to patients on prasugrel and ticagrelor as more extensive $\mathrm{P}_{2} \mathrm{Y}_{12}$ inhibitions than clopidogrel are generally observed $[64,78]$. Further, high doses of TA (30 mg/kg then $10-16 \mathrm{mg} / \mathrm{kg} /$ h) [79] may increase the incidence of postoperative seizure [80], and thus dose escalation of TA should be cautioned in patients on $\mathrm{P} 2 \mathrm{Y}_{12}$ inhibitions.

\section{Conclusions}

The recent advances in the stent designs/materials, and placement techniques have significantly reduced the incidences of MACE after PCI [81], and it may be possible to further shorten the duration of DAPT after DES implantation in the future [82]. Stent thrombosis is one of the most feared perioperative complication, and it is important to optimize the care of highrisk patients by utilizing various antiplatelet agents with different pharmacokinetics and pharmacodynamics. Routine platelet function testing in every cardiac surgical case is not warranted, but POC platelet function tests are useful in confirming residual $\mathrm{P} 2 \mathrm{Y}_{12}$ inhibition, and adjusting a waiting period before surgery $[43,51]$.

Further inter-disciplinary research efforts are needed: 1) to better stratify patients at high risk for perioperative thrombosis and/or bleeding, 2) to standardize perioperative monitoring of antithrombotic therapies, and 3) to assess multi-modal hemostatic approaches to bleeding secondary to antiplatelet therapy.

\section{References}

1. Craven LL. Experiences with aspirin (Acetylsalicylic acid) in the nonspecific prophylaxis of coronary thrombosis. Miss Valley Med J 1953; 75: 38-44.

2. Steering Committee of the Physicians' Health Study Research Group. Final report on the aspirin component of the ongoing Physicians' Health Study. N Engl J Med 1989; 321: 129-35.

3. Coller BS. Blockade of platelet GPIIb/IIIa receptors as an antithrombotic strategy. Circulation 1995; 92: 2373-80.

4. Leon MB, Baim DS, Popma JJ, Gordon PC, Cutlip DE, Ho KK, et al. A clinical trial comparing three antithrombotic-drug regimens after coronary-artery stenting. Stent Anticoagulation Restenosis Study Investigators. N Engl J Med 1998; 339: 1665-71.

5. Born GV. Aggregation of blood platelets by adenosine diphosphate and its reversal. Nature 1962; 194: 927-9.

6. Coller BS, Lang D, Scudder LE. Rapid and simple platelet function assay to assess glycoprotein IIb/IIIa receptor blockade. Circulation 1997; 95: 860-7.

7. Breet NJ, van Werkum JW, Bouman HJ, Kelder JC, Ten Berg JM, Hackeng CM. High on-aspirin platelet reactivity as measured with aggregation-based, cyclooxygenase- 1 inhibition sensitive platelet function tests is associated with the occurrence of atherothrombotic events. J Thromb Haemost 2010; 8: 2140-8.

8. Breet NJ, van Werkum JW, Bouman HJ, Kelder JC, Ruven HJ, Bal ET, et al. Comparison of platelet function tests in predicting clinical outcome in patients undergoing coronary stent implantation. JAMA 2010; 303: 754-62.

9. Hansen ML, Sørensen R, Clausen MT, Fog-Petersen ML, Raunsø J, Gadsbøll N, et al. Risk of bleeding with single, dual, or triple therapy with warfarin, aspirin, and clopidogrel in patients with atrial fibrillation. Arch Intern Med 2010; 170: 1433-41.

10. Sibbing D, Steinhubl SR, Schulz S, Schömig A, Kastrati A. Platelet aggregation and its association with stent thrombosis and bleeding in clopidogrel-treated patients: initial evidence of a therapeutic window. J Am Coll Cardiol 2010; 56: 317-8.

11. Ho PC, Triggs EJ, Bourne DW, Heazlewood VJ. The effects of age and sex on the disposition of acetylsalicylic acid and its metabolites. Br J Clin Pharmacol 1985; 19: 675-84.

12. Dacey LJ, Munoz JJ, Johnson ER, Leavitt BJ, Maloney CT, Morton JR, et al. Effect of preoperative aspirin use on mortality in coronary artery bypass grafting patients. Ann Thorac Surg 2000; 70: 1986-90.

13. Mangano DT. Aspirin and mortality from coronary bypass surgery. N Engl J Med 2002; 347: 1309-17.

14. Myles PS, Smith JA, Forbes A, Silbert B, Jayarajah M, Painter T, et al. Stopping vs. continuing aspirin before coronary artery surgery. N Engl J Med 2016; 374: 728-37.

15. Cao L, Young N, Liu H, Silvestry S, Sun W, Zhao N, et al. Preoperative aspirin use and outcomes in cardiac surgery patients. Ann Surg 2012; 255: 399-404.

16. Mazzeffi M, Galvagno S, Gammie JS, Tanaka K. Impact of aspirin use on morbidity and mortality in massively transfused cardiac surgery patients: a propensity score matched cohort study. J Anesth 2016; 30: 817-25.

17. Myles PS, Smith JA, Forbes A, Silbert B, Jayarajah M, Painter T, et al. Tranexamic acid in patients undergoing coronary-artery surgery. N Engl J Med 2017; 376: 136-48.

18. Fischman DL, Leon MB, Baim DS, Schatz RA, Savage MP, Penn I, et al. A randomized comparison of coronary-stent placement and balloon 
angioplasty in the treatment of coronary artery disease. Stent Restenosis Study Investigators. N Engl J Med 1994; 331: 496-501.

19. Eikelboom JW, Hirsh J, Spencer FA, Baglin TP, Weitz JI. Antiplatelet drugs: Antithrombotic Therapy and Prevention of Thrombosis, 9th ed: American College of Chest Physicians Evidence-Based Clinical Practice Guidelines. Chest 2012; 141(2 Suppl): e89S-e119S.

20. Hosokawa K, Ohnishi T, Sameshima H, Miura N, Ito T, Koide T, et al. Analysing responses to aspirin and clopidogrel by measuring platelet thrombus formation under arterial flow conditions. Thromb Haemost 2013; 109: 102-11.

21. Levine GN, Bates ER, Bittl JA, Brindis RG, Fihn SD, Fleisher LA, et al. 2016 ACC/AHA Guideline Focused Update on Duration of Dual Antiplatelet Therapy in Patients With Coronary Artery Disease: A Report of the American College of Cardiology/American Heart Association Task Force on Clinical Practice Guidelines. J Am Coll Cardiol 2016; 68: 1082-115.

22. Ferraris VA, Boral LI, Cohen AJ, Smyth SS, White GC 2nd. Consensus review of the treatment of cardiovascular disease in people with hemophilia A and B. Cardiol Rev 2015; 23: 53-68.

23. Kubota T, Chiba K, Ishizaki T. Genotyping of S-mephenytoin 4'-hydroxylation in an extended Japanese population. Clin Pharmacol Ther 1996; 60: 661-6.

24. Nishio R, Shinke T, Otake H, Sawada T, Haraguchi Y, Shinohara M, et al. Effect of cytochrome P450 2C19 polymorphism on target lesion outcome after drug-eluting stent implantation in japanese patients receiving clopidogrel. Circ J 2012; 76: 2348-55.

25. Farid NA, Kurihara A, Wrighton SA. Metabolism and disposition of the thienopyridine antiplatelet drugs ticlopidine, clopidogrel, and prasugrel in humans. J Clin Pharmacol 2010; 50: 126-42.

26. Montalescot G, Wiviott SD, Braunwald E, Murphy SA, Gibson CM, McCabe CH, et al. Prasugrel compared with clopidogrel in patients undergoing percutaneous coronary intervention for ST-elevation myocardial infarction (TRITON-TIMI 38): double-blind, randomised controlled trial. Lancet 2009; 373: 723-31.

27. Goodnough LT, Smith PK, Levy JH, Poston RS, Short MA, Weerakkody GJ, et al. Transfusion outcomes in patients undergoing coronary artery bypass grafting treated with prasugrel or clopidogrel: TRITON-TIMI 38 retrospective data analysis. J Thorac Cardiovasc Surg 2013; 145: 1077-82.

28. Saito S, Isshiki T, Kimura T, Ogawa H, Yokoi H, Nanto S, et al. Efficacy and safety of adjusted-dose prasugrel compared with clopidogrel in Japanese patients with acute coronary syndrome: the PRASFIT-ACS study. Circ J 2014; 78: 1684-92.

29. Nishikawa M, Isshiki T, Kimura T, Ogawa H, Yokoi H, Miyazaki S, et al. Risk of bleeding and repeated bleeding events in prasugrel-treated patients: a review of data from the Japanese PRASFIT studies. Cardiovasc Interv Ther 2017; 32: 93-105.

30. Teng R, Oliver S, Hayes MA, Butler K. Absorption, distribution, metabolism, and excretion of ticagrelor in healthy subjects. Drug Metab Dispos 2010; 38: 1514-21.

31. Becker RC, Bassand JP, Budaj A, Wojdyla DM, James SK, Cornel JH, et al. Bleeding complications with the P2Y12 receptor antagonists clopidogrel and ticagrelor in the PLATelet inhibition and patient Outcomes (PLATO) trial. Eur Heart J 2011; 32: 2933-44.

32. Hansson EC, Jidéus L, Åberg B, Bjursten H, Dreifaldt M, Holmgren A, et al. Coronary artery bypass grafting-related bleeding complications in patients treated with ticagrelor or clopidogrel: a nationwide study. Eur Heart J 2016; 37: 189-97.

33. Mehran R, Rao SV, Bhatt DL, Gibson CM, Caixeta A, Eikelboom J, et al. Standardized bleeding definitions for cardiovascular clinical trials: a consensus report from the Bleeding Academic Research Consortium. Circulation 2011; 123: 2736-47.

34. Norgard NB. Cangrelor: a novel P2Y12 receptor antagonist. Expert Opin Investig Drugs 2009; 18: 1219-30.

35. Akers WS, Oh JJ, Oestreich JH, Ferraris S, Wethington M, Steinhubl SR. Pharmacokinetics and pharmacodynamics of a bolus and infusion of cangrelor: a direct, parenteral P2Y12 receptor antagonist. J Clin Pharmacol 2010; 50: 27-35.

36. Medicines Company. Kengreal (cangrelor) Full Prescribing Information [cited 2017 Jun 20]. Available from https://www.accessdata.fda.gov/ drugsatfda_docs/label/2015/204958lbl.pdf

37. Bhatt DL, Stone GW, Mahaffey KW, Gibson CM, Steg PG, Hamm CW, et al. Effect of platelet inhibition with cangrelor during PCI on ischemic events. N Engl J Med 2013; 368: 1303-13.

38. Angiolillo DJ, Firstenberg MS, Price MJ, Tummala PE, Hutyra M, Welsby IJ, et al. Bridging antiplatelet therapy with cangrelor in patients undergoing cardiac surgery: a randomized controlled trial. JAMA 2012; 307: 265-74.

39. Kirchmaier CM, Pillitteri D. Diagnosis and management of inherited platelet disorders. Transfus Med Hemother 2010; $37: 237-46$.

40. Flechtenmacher N, Kämmerer F, Dittmer R, Budde U, Michels P, Röther J, et al. Clopidogrel resistance in neurovascular stenting: correlations between light transmission aggregometry, verifynow, and the multiplate. AJNR Am J Neuroradiol 2015; 36: 1953-8.

41. Jakubowski JA, Payne CD, Li YG, Brandt JT, Small DS, Farid NA, et al. The use of the VerifyNow P2Y 12 point-of-care device to monitor platelet function across a range of $\mathrm{P}_{2} \mathrm{Y}_{12}$ inhibition levels following prasugrel and clopidogrel administration. Thromb Haemost 2008; 99: 409-15.

42. Nishi T, Ariyoshi N, Nakayama T, Fujimoto Y, Sugimoto K, Takahara M, et al. Increased platelet inhibition after switching from maintenance clopidogrel to prasugrel in Japanese patients with stable coronary artery disease. Circ J 2015; 79: 2439-44.

43. Benzon HT, McCarthy RJ, Benzon HA, Kendall MC, Robak S, Lindholm PF, et al. Determination of residual antiplatelet activity of clopidogrel before neuraxial injections. Br J Anaesth 2011; 107: 966-71.

44. Kakouros N, Kickler TS, Laws KM, Rade JJ. Hematocrit alters VerifyNow P2 $\mathrm{Y}_{12}$ assay results independently of intrinsic platelet reactivity and clopidogrel responsiveness. J Thromb Haemost 2013; 11: 1814-22.

45. Sibbing D, Schulz S, Braun S, Morath T, Stegherr J, Mehilli J, et al. Antiplatelet effects of clopidogrel and bleeding in patients undergoing 
coronary stent placement. J Thromb Haemost 2010; 8: 250-6.

46. Weber CF, Görlinger K, Meininger D, Herrmann E, Bingold T, Moritz A, et al. Point-of-care testing: a prospective, randomized clinical trial of efficacy in coagulopathic cardiac surgery patients. Anesthesiology 2012; 117: 531-47.

47. Mazzeffi M, Lund L, Wallace K, Herrera AV, Tanaka K, Odonkor P, et al. Effect of cardiopulmonary bypass on platelet mitochondrial respiration and correlation with aggregation and bleeding: a pilot study. Perfusion 2016; 31: 508-15.

48. Hobson AR, Petley GW, Dawkins KD, Curzen N. A novel fifteen minute test for assessment of individual time-dependent clotting responses to aspirin and clopidogrel using modified thrombelastography. Platelets 2007; 18: 497-505.

49. Sambu N, Hobson A, Curzen N. "Short" thrombelastography as a test of platelet reactivity in response to antiplatelet therapy: validation and reproducibility. Platelets 2011; 22: 210-6.

50. Collyer TC, Gray DJ, Sandhu R, Berridge J, Lyons G. Assessment of platelet inhibition secondary to clopidogrel and aspirin therapy in preoperative acute surgical patients measured by Thrombelastography Platelet Mapping. Br J Anaesth 2009; 102: 492-8.

51. Mahla E, Suarez TA, Bliden KP, Rehak P, Metzler H, Sequeira AJ, et al. Platelet function measurement-based strategy to reduce bleeding and waiting time in clopidogrel-treated patients undergoing coronary artery bypass graft surgery: the timing based on platelet function strategy to reduce clopidogrel-associated bleeding related to CABG (TARGET-CABG) study. Circ Cardiovasc Interv 2012; 5: 261-9.

52. Xiao Z, Théroux P. Platelet activation with unfractionated heparin at therapeutic concentrations and comparisons with a low-molecularweight heparin and with a direct thrombin inhibitor. Circulation 1998; 97: 251-6.

53. Mochizuki T, Olson PJ, Szlam F, Ramsay JG, Levy JH. Protamine reversal of heparin affects platelet aggregation and activated clotting time after cardiopulmonary bypass. Anesth Analg 1998; 87: 781-5.

54. Michelson AD, MacGregor H, Barnard MR, Kestin AS, Rohrer MJ, Valeri CR. Reversible inhibition of human platelet activation by hypothermia in vivo and in vitro. Thromb Haemost 1994; 71: 633-40.

55. Hoffmeister KM, Felbinger TW, Falet H, Denis CV, Bergmeier W, Mayadas TN, et al. The clearance mechanism of chilled blood platelets. Cell 2003; 112: 87-97.

56. Karkouti K, McCluskey SA, Syed S, Pazaratz C, Poonawala H, Crowther MA. The influence of perioperative coagulation status on postoperative blood loss in complex cardiac surgery: a prospective observational study. Anesth Analg 2010; 110: 1533-40.

57. Velik-Salchner C, Maier S, Innerhofer P, Kolbitsch C, Streif W, Mittermayr M, et al. An assessment of cardiopulmonary bypass-induced changes in platelet function using whole blood and classical light transmission aggregometry: the results of a pilot study. Anesth Analg 2009; 108: 1747-54.

58. Van Poucke S, Stevens K, Wetzels R, Kicken C, Verhezen P, Theunissen M, et al. Early platelet recovery following cardiac surgery with cardiopulmonary bypass. Platelets 2016; 27: 751-7.

59. Rahe-Meyer N, Winterhalter M, Boden A, Froemke C, Piepenbrock S, Calatzis A, et al. Platelet concentrates transfusion in cardiac surgery and platelet function assessment by multiple electrode aggregometry. Acta Anaesthesiol Scand 2009; 53: 168-75.

60. Weitzel NS, Weitzel LB, Epperson LE, Karimpour-Ford A, Tran ZV, Seres T. Platelet mapping as part of modified thromboelastography $\left(\mathrm{TEG}^{\circledR}\right)$ in patients undergoing cardiac surgery and cardiopulmonary bypass. Anaesthesia 2012; 67: 1158-65.

61. Orlov D, McCluskey SA, Callum J, Rao V, Moreno J, Karkouti K. Utilization and effectiveness of desmopressin acetate after cardiacsurgery supplemented with point-of-care hemostatic testing: a propensity-score-matched analysis. J Cardiothorac Vasc Anesth 2017; 31 : 883-95.

62. Karkouti K, Callum J, Wijeysundera DN, Rao V, Crowther M, Grocott HP, et al. Point-of-care hemostatic testing in cardiac surgery: a stepped-wedge clustered randomized controlled trial. Circulation 2016; 134: 1152-62.

63. Zafar MU, Santos-Gallego C, Vorchheimer DA, Viles-Gonzalez JF, Elmariah S, Giannarelli C, et al. Platelet function normalization after a prasugrel loading-dose: time-dependent effect of platelet supplementation. J Thromb Haemost 2013; 11: 100-6.

64. Hansson EC, Shams Hakimi C, Åström-Olsson K, Hesse C, Wallén H, Dellborg M, et al. Effects of ex vivo platelet supplementation on platelet aggregability in blood samples from patients treated with acetylsalicylic acid, clopidogrel, or ticagrelor. Br J Anaesth 2014; 112: 5705 .

65. Vilahur G, Choi BG, Zafar MU, Viles-Gonzalez JF, Vorchheimer DA, Fuster V, et al. Normalization of platelet reactivity in clopidogreltreated subjects. J Thromb Haemost 2007; 5: 82-90.

66. Akay OM, Gündüz E, Başyiğit H, Gulbas Z. Platelet function testing during 5-day storage of single and random donor plateletpheresis. Transfus Apher Sci 2007; 36: 285-9.

67. Prüller F, Drexler C, Archan S, Macher S, Raggam RB, Mahla E. Low platelet reactivity is recovered by transfusion of stored platelets: a healthy volunteer in vivo study. J Thromb Haemost 2011; 9: 1670-3.

68. Dalén M, Ivert T, Lindvall G, van der Linden J. Ticagrelor-associated bleeding in a patient undergoing surgery for acute type A aortic dissection. J Cardiothorac Vasc Anesth 2013; 27: e55-7.

69. Hedner U. NovoSeven as a universal haemostatic agent. Blood Coagul Fibrinolysis 2000; 11 Suppl 1: S107-11.

70. Levi M, Levy JH, Andersen HF, Truloff D. Safety of recombinant activated factor VII in randomized clinical trials. N Engl J Med 2010; 363 : $1791-800$.

71. Skolnick BE, Shenouda M, Khutoryansky NM, Pusateri AE, Gabriel D, Carr ME. Reversal of clopidogrel-induced bleeding with rFVIIa in healthy subjects: a randomized, placebo-controlled, double-blind, exploratory study. Anesth Analg 2011; 113: 703-10.

72. Gill R, Herbertson M, Vuylsteke A, Olsen PS, von Heymann C, Mythen M, et al. Safety and efficacy of recombinant activated factor VII: a 
randomized placebo-controlled trial in the setting of bleeding after cardiac surgery. Circulation 2009; 120: 21-7.

73. Branchford BR, Di Paola J. Making a diagnosis of VWD. Hematology Am Soc Hematol Educ Program 2012; 2012: 161-7.

74. Mannucci PM. Desmopressin (DDAVP) in the treatment of bleeding disorders: the first 20 years. Blood 1997; 90: 2515-21.

75. Crescenzi G, Landoni G, Biondi-Zoccai G, Pappalardo F, Nuzzi M, Bignami E, et al. Desmopressin reduces transfusion needs after surgery: a meta-analysis of randomized clinical trials. Anesthesiology 2008; 109: 1063-76.

76. Swieringa F, Lancé MD, Fuchs B, Feijge MA, Solecka BA, Verheijen LP, et al. Desmopressin treatment improves platelet function under flow in patients with postoperative bleeding. J Thromb Haemost 2015; 13: 1503-13.

77. Ferraris VA, Saha SP, Oestreich JH, Song HK, Rosengart T, Reece TB, et al. 2012 update to the Society of Thoracic Surgeons guideline on use of antiplatelet drugs in patients having cardiac and noncardiac operations. Ann Thorac Surg 2012; 94: 1761-81.

78. Trenk D, Stone GW, Gawaz M, Kastrati A, Angiolillo DJ, Müller U, et al. A randomized trial of prasugrel versus clopidogrel in patients with high platelet reactivity on clopidogrel after elective percutaneous coronary intervention with implantation of drug-eluting stents: results of the TRIGGER-PCI (Testing Platelet Reactivity In Patients Undergoing Elective Stent Placement on Clopidogrel to Guide Alternative Therapy With Prasugrel) study. J Am Coll Cardiol 2012; 59: 2159-64.

79. Fergusson DA, Hébert PC, Mazer CD, Fremes S, MacAdams C, Murkin JM, et al. A comparison of aprotinin and lysine analogues in highrisk cardiac surgery. N Engl J Med 2008; 358: 2319-31.

80. Martin K, Wiesner G, Breuer T, Lange R, Tassani P. The risks of aprotinin and tranexamic acid in cardiac surgery: a one-year follow-up of 1188 consecutive patients. Anesth Analg 2008; 107: 1783-90.

81. Witzenbichler B, Maehara A, Weisz G, Neumann FJ, Rinaldi MJ, Metzger DC, et al. Relationship between intravascular ultrasound guidance and clinical outcomes after drug-eluting stents: the assessment of dual antiplatelet therapy with drug-eluting stents (ADAPT-DES) study. Circulation 2014; 129: 463-70.

82. Feres F, Costa RA, Abizaid A, Leon MB, Marin-Neto JA, Botelho RV, et al. Three vs twelve months of dual antiplatelet therapy after zotarolimus-eluting stents: the OPTIMIZE randomized trial. JAMA 2013; 310: 2510-22. 